\title{
Analisis Kebutuhan Steam pada Proses Penyeduhan Daun Teh di Unit Extract Tank PT. XYZ Tanjung Morawa
}

\author{
Dimas Frananta Simatupang ${ }^{* 1}$, Ratna Kristina Tarigan², Soherawati Rospa Ginting ${ }^{3}$ \\ ${ }^{1,2,3}$ Program Studi Teknik Kimia, Politeknik Teknologi Kimia Industri Medan, Indonesia \\ Email: ${ }^{1}$ difratas@ptki.ac.id, ${ }^{2}$ ratnakristina@ptki.ac.id, ${ }^{3}$ soherawatirospag@gmail.com
}

\begin{abstract}
Abstrak
Daun teh yang merupakan bagian penting dari tanaman teh dapat diolah menjadi minuman teh dalam kemasan yang menjadi produk utama PT. XYZ Tanjung Morawa. Kunci keberhasilan pada produksi minuman teh dalam kemasan adalah penyeduhan daun teh yang menggunakan air panas bersuhu $90-95^{\circ} \mathrm{C}$ dimana air dipanaskan menggunakan steam di unit extract tank dengan bantuan alat plate heat exchanger. Penentuan banyaknya steam dalam proses penyeduhan daun teh diperlukan untuk menghitung nilai panas yang dilepas ke lingkungan atau yang diserap oleh daun teh selama proses penyeduhan daun teh di unit extract tank sebagai data tambahan dan informasi pendukung pabrik. Dalam penelitian ini dilakukan analisa kebutuhan steam pada proses penyeduhan daun teh dengan mengumpulkan data sekunder yang langsung diperoleh dari pabrik dan menghitung jumlah panas dari komponen bahan dengan stoikiometri dan konsep panas untuk menentukan kebutuhan steam. Berdasarkan hasil perhitungan diperoleh bahwa dengan rata-rata suhu air panas dengan laju air sebesar 5500 L/jam maka jumlah panas yang dibutuhkan sebanyak 1.454.700,012 Kkal/jam dan steam yang dibutuhkan sebanyak $3840,6481 \mathrm{Kg} / \mathrm{jam}$ dalam proses penyeduhan daun teh sebanyak 40-50 Kg.
\end{abstract}

Kata kunci: Extract Tank, Panas, Penyeduhan Daun Teh, Steam

\section{Analysis of Steam Requirements for Tea Leaf Brewing Process in Extract Tank Unit PT. XYZ Tanjung Morawa}

\begin{abstract}
Tea leaves are the important parts of tea plants that can be processed into packaged tea drinks which are the main product of PT. XYZ Tanjung Morawa. The main key in the production of packaged tea drinks is brewing the tea leaves using hot water with temperature range of $90-95{ }^{\circ} \mathrm{C}$ where the water is heated using steam in the extract tank unit with support of a plate heat exchanger. Determination of the amount of steam in tea leaf brewing process is needed to calculate the value of heat released to the environment or absorbed by the tea leaves during the tea leaf brewing process in the extract tank unit as additional data and plant supporting information. In this study, an analysis of steam requirements in tea leaf brewing process was carried out by collecting secondary data directly obtained from the plant and calculating the amount of heat from the material components using stoichiometry and heat concepts to determine steam requirements. Based on the calculation results, it was revealed that with an average temperature of hot water with water rate of 5500 L/hour, the amount of heat needed was 1,454,700.012 Kcal/hour and the steam required was 3840.6481 Kg/hour in the brewing process of $40-50 \mathrm{Kg}$.
\end{abstract}

Keywords: Extract Tank, Heat, Tea Leaf Brewing, Steam

\section{PENDAHULUAN}

Teh dibuat dari daun tanaman teh yang dikenal dengan Camellia sinensis dan telah melalui beberapa proses. Selain air, teh juga merupakan minuman yang paling banyak dikonsumsi di dunia. Daun teh umumnya diklasifikasikan menjadi beberapa jenis diantaranya adalah teh hijau yang tidak difermentasi, teh oolong yang dihasilkan melalui proses semi fermentasi dan teh hitam yang biasanya difermentasi. Teh hijau merupakan teh utama yang diproduksi dan dikonsumsi di Asia. Senyawa kimia dalam kandungan teh yang telah diseduh memberikan banyak manfaat untuk kesehatan tubuh [1], [2]. 
PT. XYZ Tanjung Morawa merupakan pabrik pengolahan daun teh yang mengolah daun teh menjadi suatu produk minuman teh dalam kemasan. Salah satu proses penting dalam proses produksi minuman teh dalam kemasan yaitu proses penyeduhan daun teh yang masih segar. Daun teh ini dipilih untuk mendapatkan hasil yang baik dengan rasa dan warna yang segar serta aroma yang harum yang sesuai dengan selera konsumen. Penyeduhan daun teh ini dilakukan pada unit extract tank dengan teknik ekstraksi padat-cair yaitu daun teh dan air dimana extract tank tersebut memiliki volume maksimal 6000 liter air dengan daun teh berkisar sebanyak 40$50 \mathrm{~kg}$ dengan temperatur air masuk $30{ }^{\circ} \mathrm{C}$ dan suhu penyeduhan $90-95{ }^{\circ} \mathrm{C}$. Di dalam extract tank tersebut terdapat saringan yang berguna untuk menyaring hasil ekstrak dari daun teh yang disebut dengan teh cair pahit yang untuk dikirim ke tahap selanjutnya. Dan di dalam extract tank tersebut juga terdapat alat pengaduk yang berfungsi sebagai mengaduk daun teh yang diekstrak dengan air supaya tidak terjadi pengendapan. Indikator keberhasilan pada proses ekstraksi ini adalah sesuai dengan SNI-01-3134-1992 [3].

Pada proses penyeduhan daun teh, uap panas (steam) digunakan sebagai pemanas air untuk mengekstrak daun teh tersebut. Proses pemanasan air dilakukan dengan bantuan alat Plate Heat Exchanger (PHE) yang merupakan alat penukar panas antara dua fluida yang memiliki perbedaan suhu dimana satu fluida akan memberikan panas dan fluida lainnya akan menerima panas. Alat ini menerapkan prinsip perpindahan kalor yang umumnya memiliki bentuk frame yang diberi plat sebagai sekat-sekat [4]-[6]. Berbeda halnya dengan steam yang digunakan pada pengolahan CPO di pabrik kelapa sawit yang diproduksi melalui ketel uap (boiler) dengan batu bara sebagai sumber energi [7]-[9]. PHE memiliki beberapa keunggulan dibandingkan penukar panas tabung lainnya seperti biaya yang rendah, penghematan energi dan fleksibilitasnya dalam mengubah area permukaan perpindahan panas. Hal ini memungkinkah PHE memenuhi beban panas dan tekanan yang dibutuhkan aliran panas dan dingin. Namun terdapat kelemahan PHE yang ditemukan seperti terjadinya kebocoran pada pelat yang diakibatkan adanya gasket pada seal yang rusak akibat life time alat dan pemasangan pelat-pelat harus diperhatikan teliti untuk menentukan besarnya torsi yang mempengaruhi bentuk dari pelat itu sendiri [10], [11].

Uap panas (steam) ini perlu diketahui dan ditentukan kebutuhannya untuk menyeduh daun teh dalam proses penyeduhan untuk menghasilkan produk yang bermutu baik. Adapun tujuan dalam penelitian ini adalah untuk menganalisis banyaknya steam yang diperlukan pada proses penyeduhan daun teh di unit extract tank menggunakan pendekatan konsep perhitungan panas sehingga nantinya dapat menambah informasi kebutuhan steam dalam proses penyeduhan daun teh sebagai tahap awal dalam produksi minuman teh dalam kemasan.

\section{METODE PENELITIAN}

\subsection{Pengumpulan Data}

Penelitian dilakukan dengan mengumpulkan data sekunder dari pabrik PT. XYZ Tanjung Morawa khususnya pada unit extract tank yang meliputi data laju alir air panas, suhu air panas dan data pada pemanasan di PHE (suhu steam, suhu air, suhu kondensat dan tekanan steam). Data ini diambil pada saat pabrik beroperasi selama tiga hari berturut-turut. Seluruh data yang terkumpul selanjutnya dilakukan pengolahan data dan analisis dengan konsep perhitungan panas.

\subsection{Analisa Data}

Pengolahan data diawali dengan menghitung massa air pada kondisi suhu terukur dengan persamaan :

$$
m=\rho \times V
$$

dengan $m$ adalah massa air, $\rho$ adalah massa jenis air dan $\mathrm{V}$ adalah laju alir air [12]. Selanjutnya dilakukan penentuan mol bahan yang masuk dengan konsep mol yang meliputi air dan natrium bikarbonat $\left(\mathrm{NaHCO}_{3}\right)$ yang diduga berfungsi sebagai bahan aktif untuk mempertahankan warna dan kandungan antioksidan dalam daun teh selama proses pengolahan. Ion hidrogen dalam natrium bikarbonat diduga akan masuk ke dalam struktur klorofil (pigmen dalam fotosintesis) [13] pada daun teh dan dapat mengurangi kerusakan struktur klorofil selama proses penyeduhan daun teh sehingga zat aktif antioksidannya dapat dijaga [14].

Kemudian dilakukan penentuan panas dari air $\left(\mathrm{Q}_{\text {air }}\right)$ dan natrium bikarbonat $\left(\mathrm{Q}_{\mathrm{NAHCO} 3}\right)$ dengan persamaan :

$$
\begin{aligned}
& Q=m \int C_{p} d T \\
& Q=m \int_{T 1}^{T 2} a+b T+c T^{2}+d T^{3}
\end{aligned}
$$


dengan Cp merupakan kapasitas panas dan dT merupakan selisih suhu air panas dengan suhu air pada PHE dalam satuan Kelvin. Nilai a, b, c dan d dapat dilihat pada tabel liquid heat capacities [15], [16]. Setelah diperoleh nilai panas air dan nilai panas natrium bikarbonat (Kkal/jam) maka total panas $\left(\mathrm{Q}_{\text {extract tank }}\right)$ yang dibutuhkan pada proses penyeduhan daun teh di unit extract tank dapat ditentukan dengan persamaan :

$$
Q_{\text {extract tank }}=Q_{\text {air }}+Q_{\mathrm{NaHCO}_{3}}
$$

Total panas yang dibutuhkan pada proses penyeduhan daun teh sama dengan panas yang dilepas oleh steam $\left(\mathrm{Q}_{\text {steam }}\right)$ selama proses pengolahan.

Setelah diperoleh panas yang dilepas oleh steam, selanjutnya menentukan jumlah steam $\left(\mathrm{m}_{\text {steam }}\right)$ yang dibutuhkan selama proses penyeduhan daun teh dengan persamaan :

$$
Q_{\text {steam }}=m_{\text {steam }} \times \lambda_{\text {steam }}
$$

dengan $\lambda_{\text {steam }}$ merupakan entalpi panas steam yang ditentukan terlebih dahulu menggunakan persamaan :

$$
\lambda_{\text {steam }}=H s-H c
$$

dimana Hs merupakan entalpi panas steam pada suhu $85{ }^{\circ} \mathrm{C}(463,8273 \mathrm{Kkal} / \mathrm{Kg})$ dan $\mathrm{Hc}$ merupakan entalpi panas kondensat $(85,0601 \mathrm{Kkal} / \mathrm{Kg})[15]$.

\section{HASIL DAN PEMBAHASAN}

Steam yang digunakan pada proses penyeduhan daun teh di unit extract tank berfungsi untuk memanaskan air hingga suhu yang ditentukan yang akan digunakan untuk menyeduh daun teh dan menghasilkan teh cair pahit (TCP) yang akan diolah lebih lanjut ke tahap berikutnya dan terdapat ampas teh kering sebagai produk sisa. Proses pemanasan air ini dilakukan dengan bantuan alat Plate Heat Exchanger (PHE). Jumlah uap yang tidak mencukupi, dapat menyebabkan proses penyeduhan tidak berjalan dengan baik. Jika steam yang diinjeksikan pada Plate Heat Exchanger tidak mencukupi maka proses penyeduhan tidak berjalan dengan maksimal sehingga dapat mengakibatkan dampak sangat buruk bagi produk teh dalam kemasan dikarenakan produk tersebut tidak dapat dikonsumsi. Skema proses penyeduhan daun teh dideskripsikan pada gambar 1. Adanya penambahan natrium bikarbonat dalam proses penyeduhan daun teh berguna untuk menjaga struktur klorofil agar tidak rusak dan kandungan antioksidan tetap baik dalam produk minuman teh kemasan.

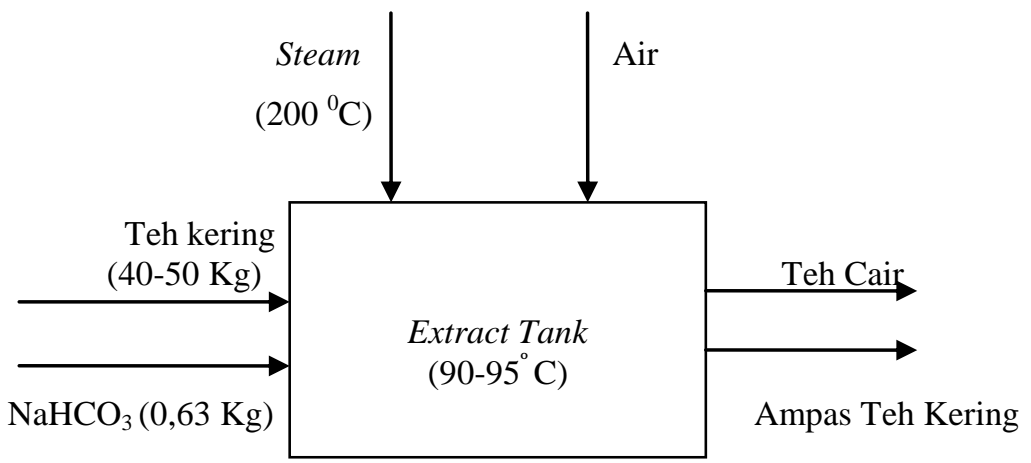

Gambar 1. Skema proses penyeduhan daun teh

Data-data sekunder yang diperoleh dari pabrik dengan pengamatan sebanyak tiga kali selama tiga hari berturut-turut meliputi suhu air panas yang digunakan, laju alir air panas, dan data pada pemanasan di PHE (suhu steam, suhu air, suhu kondensat dan tekanan steam). Pengamatan dilakukan dengan kondisi alat yang sama dan melakukan wawancara lisan dengan teknisi operator. Data-data sekunder sebagai data dasar untuk melakukan penentuan kebutuhan steam pada proses penyeduhan daun teh disajikan pada tabel 1 .

Tabel 1. Data Sekunder Penyeduhan Daun Teh di Extract Tank

\begin{tabular}{ccccccc}
\hline $\begin{array}{c}\text { Pengamatan } \\
\text { Hari Ke- }\end{array}$ & \multicolumn{2}{c}{ Air Panas yang Digunakan } & \multicolumn{5}{c}{ Pemanasan di PHE } \\
\cline { 2 - 7 }$\left({ }^{\circ} \mathrm{C}\right)$ & $\begin{array}{c}\text { Laju alir } \\
(\mathrm{L} / \mathrm{jam})\end{array}$ & $\begin{array}{c}\text { Suhu Steam } \\
\left({ }^{\circ} \mathrm{C}\right)\end{array}$ & $\begin{array}{c}\text { Suhu Air } \\
\left({ }^{\circ} \mathrm{C}\right)\end{array}$ & $\begin{array}{c}\text { Suhu Kondensat } \\
\left({ }^{\circ} \mathrm{C}\right)\end{array}$ & $\begin{array}{c}\text { Tekanan } \\
\text { Steam }(\mathrm{bar})\end{array}$ \\
\hline 1 & 91 & 5500 & & & & 4 \\
2 & 92 & 5500 & 200 & 30 & 85 & 4
\end{tabular}




$3 \quad 93 \quad 5500$

Suhu air panas yang terukur selama tiga kali pengamatan berbeda-beda dengan laju alir air panas yang digunakan tetap sebanyak $5500 \mathrm{~L} / \mathrm{jam}$. Melalui persamaan (1) diperoleh massa air sebesar 5476,02 Kg/jam dengan massa jenis air yang digunakan senilai $0,99561 \mathrm{~g} / \mathrm{mL}$. Selanjutnya diperoleh data mol air dan mol natrium bikarbonat masing-masing sebanyak 304223,3333 mol/jam dan 7,5 mol/jam dari 0,63 Kg/jam natrium bikarbonat yang masuk ke unit extract tank. Kemudian berdasarkan hasil perhitungan dengan persamaan (2) dan dilanjutkan ke persamaan (3) maka dapat diperoleh total panas $\left(Q_{\text {extract tank }}\right)$ yang dibutuhkan pada proses penyeduhan daun teh di unit extract tank dengan rata-rata sebesar $1.454 .700,012 \mathrm{Kkal} / \mathrm{jam}$. Lebih lanjut dalam penentuan jumlah steam yang dibutuhkan maka terlebih dahulu ditentukan entalpi panas steam melalui persamaan (5) dan diperoleh bahwa nilai entalpi panas steam sebesar 378,7642 Kkal/kg. Nilai entalpi panas steam ini digunakan dalam perhitungan jumlah steam dengan persamaan (4). Tabulasi perhitungan panas ditunjukkan pada tabel 2. Berdasarkan hasil perhitungan maka dapat diperoleh jumlah steam rata-rata yang dibutuhkan pada proses penyeduhan daun teh sebesar 3840,6481 Kg/jam.

Tabel 2. Tabulasi Perhitungan Panas dan Jumlah Steam Pada Penyeduhan Daun Teh di Extract Tank

\begin{tabular}{|c|c|c|c|c|c|c|c|c|}
\hline \multirow[b]{2}{*}{$\begin{array}{c}\text { Pengamatan } \\
\text { Hari Ke- }\end{array}$} & \multicolumn{2}{|c|}{$\begin{array}{c}\text { Air Panas yang } \\
\text { Digunakan }\end{array}$} & \multicolumn{4}{|c|}{ Pemanasan di PHE } & \multirow[b]{2}{*}{$\begin{array}{l}\text { Total Panas } \\
\text { (Kkal/jam) }\end{array}$} & \multirow{2}{*}{$\begin{array}{l}\text { Kebutuhan } \\
\text { Jumlah Steam } \\
\text { (Kg/jam) }\end{array}$} \\
\hline & $\begin{array}{l}\text { Suhu } \\
\left({ }^{\circ} \mathrm{C}\right)\end{array}$ & $\begin{array}{c}\text { Laju } \\
\text { alir } \\
\text { (L/jam) }\end{array}$ & $\begin{array}{l}\text { Suhu } \\
\text { Steam } \\
\left({ }^{\circ} \mathrm{C}\right)\end{array}$ & $\begin{array}{l}\text { Suhu } \\
\text { Air } \\
\left({ }^{\circ} \mathrm{C}\right)\end{array}$ & $\begin{array}{c}\text { Suhu } \\
\text { Kondensat } \\
\left({ }^{\circ} \mathrm{C}\right)\end{array}$ & $\begin{array}{c}\text { Tekanan } \\
\text { Steam } \\
\text { (bar) }\end{array}$ & & \\
\hline 1 & 91 & 5500 & \multirow{3}{*}{200} & \multirow{4}{*}{30} & \multirow{4}{*}{85} & \multirow{4}{*}{4} & 1449173,152 & 3826,0563 \\
\hline 2 & 92 & 5500 & & & & & 1454710,153 & 3840,6749 \\
\hline \multirow[t]{2}{*}{3} & 93 & 5500 & & & & & 1460216,73 & 3855,2132 \\
\hline & & & Rata-rata & & & & 1454700,012 & 3840,6481 \\
\hline
\end{tabular}

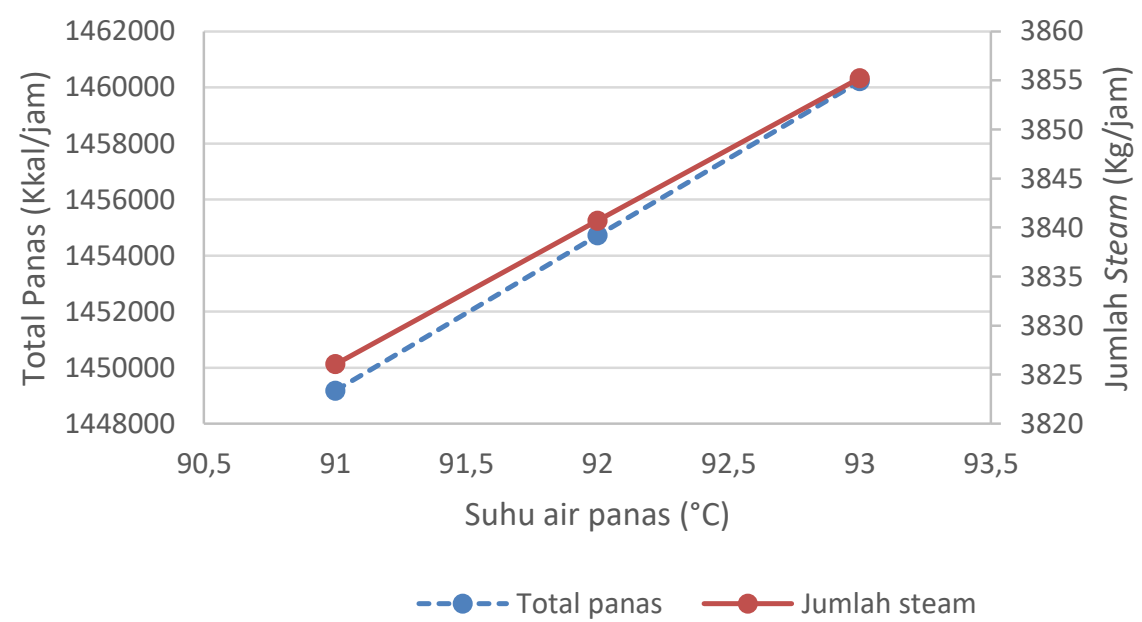

Gambar 2. Profil suhu air panas terhadap total panas dan jumlah steam

Adanya peningkatan suhu air panas yang digunakan pada proses penyeduhan daun teh juga meningkatkan total panas di unit extract tank dan berbanding lurus dengan kebutuhan jumlah steam sehingga PHE yang digunakan untuk memanaskan air pun akan semakin meningkat kinerja alatnya. Suhu air panas pada umumnya dijaga direntang $90-95{ }^{\circ} \mathrm{C}$ untuk menjaga kualitas produk teh cair pahit yang nantinya diproses menjadi minuman teh dalam kemasan.

\section{KESIMPULAN}

Berdasarkan hasil analisa dan perhitungan yang telah dijelaskan sebelumnya maka dapat disimpulkan bahwa rata-rata total panas dan jumlah steam yang dibutuhkan pada proses penyeduhan daun teh di unit extract tank PT. XYZ Tanjung Morawa adalah masing-masing sebesar 1.454.700,012 Kkal/jam dan 3840,6481 Kg/jam 
dengan rentang suhu air panas yang digunakan berkisar antara 91-93 ${ }^{0} \mathrm{C}$. Semakin tinggi suhu air panas yang digunakan maka semakin tinggi pula total panas dan jumlah steam yang dibuthkan pada proses penyeduhan daun teh tersebut.

\section{DAFTAR PUSTAKA}

[1] M. Franks, P. Lawrence, A. Abbaspourrad, and R. Dando, "The influence of water composition on flavor and nutrient extraction in green and black tea," Nutrients, vol. 11, no. 1, 2019, doi: 10.3390/nu11010080.

[2] J. A. Sánchez-López et al., "Extraction kinetics of tea aroma compounds as a function brewing temperature, leaf size and water hardness," Flavour Fragr. J., vol. 35, no. 4, pp. 365-375, 2020, doi: 10.1002/ffj.3571.

[3] PT. XYZ, "Katalog PT. XYZ,” Tanjung Morawa, 2019.

[4] H. S. F. Egeten, F. P. Sappu, and B. Maluegha, "Efektivitas Penukar Kalor Tipe Plate P41 73 TK di PLTP Lahendong Unit 2,” J. Online Poros Tek. Mesin, vol. 3, no. 1, pp. 67-76, 2014.

[5] R. G. Saputra and A. B. P. Khrisna, "Studi Eksperimen Analisa Performa Compact Heat Exchanger Circular Tubes Continuous Plate Fin Untuk Pemanfataan Waste Energy,” J. Tek. Pomits, vol. 3, no. 1, pp. 104-107, 2014.

[6] I. Putra, "Studi perhitungan heat exchanger type shell and tube dehumidifier biogas limbah sawit untuk pembangkit listrik tenaga biogas," J. POLIMESIN, vol. 15, no. 2, p. 42, 2017, doi: 10.30811/jpl.v15i2.373.

[7] D. F. Simatupang, Yunianto, and E. D. W. Sihaloho, "Analisa Kebutuhan Batu Bara pada Unit Dryer dalam Pengeringan Pupuk NPK di PT AGS Medan,” CHEESA Chem. Eng. Res. Artic., vol. 4, no. 1, pp. 11-17, 2021, doi: 10.25273/cheesa.v4i1.7830.11-17.

[8] D. F. Simatupang, G. Saragih, and D. M. C. Simbolon, "Studi Penentuan Perolehan dan Kehilangan Minyak dari Lumpur Buangan Proses pada Unit Decanter di Pabrik Kelapa Sawit PT. SPTG," in Seminar Nasional Teknologi Industri VII, 2021, pp. 376-382.

[9] D. F. Simatupang and Ramadhani, "Penentuan Kebutuhan Injeksi Ammonia untuk Meningkatkan pH pada Air Umpan Boiler : Studi Kasus di PT . XYZ Sumatera Utara,” J. Pendidik. dan Teknol. Indones., vol. 1, no. 5, pp. 187-191, 2021, doi: 10.52436/1.jpti.42.

[10] I. Bizzy and R. Setiadi, "Studi Perhitungan Alat Penukar Kalor Tipe Shell and Tube Dengan Program Heat Transfer Research Inc. ( Htri ),” J. Rekayasa Mesin Univ. Sriwij., vol. 13, no. 1, pp. 67-76, 2013.

[11] M. S. Atikayanti, S. F. Nur, B. Santoso, and A. Ekayuliana, "Analisis Perbandingan Heat Exchanger Tipe Plate-Frame Dan Shell And Tube Pada Intercooler,” in Seminar Nasional Teknik Mesin, 2018, pp. 335-345.

[12] J. P. Witoko, D. Haryanto, Giarno, M. H. Kusuma, M. Juarsa, and A. R. Antariksawan, "Perhitungan Kebutuhan Daya Heater Pada Kolam Pemanas Heat Pipe," in Seminar Nasional Mesin dan Industri (SNMI XII), 2018, no. April, pp. 68-72.

[13] D. F. Simatupang, F. Madayanti, B. Bundjali, and A. Akhmaloka, "Investigation of aqueous-methanol extract from red marine macroalgae Gracilaria verrucosa as inhibitor for biocorrosion," Asian J. Microbiol. Biotechnol. Environ. Sci., vol. 20, no. 1, pp. 100-107, 2018.

[14] M. P. Kurniawan, F. W. Ma'ruf, and T. W. Agustini, "Pengaruh Penambahan MgCO3 dan NaHCO3 dengan Perbedaan Pencahayaan Terhadap Stabilitas Pigmen Klorofil-A Mikroalga Chlorella vulgaris,” J. Pengolah. dan Bioteknol. Has. Perikan., vol. 2, no. 3, pp. 25-33, 2013.

[15] G. V Reklaitis, Introduction to Material and Energy Balances. United States of America: John \&Wiley \& Sons, Inc, 1983.

[16] Sulaiman and R. Randa, "Pengaruh Temperatur Terhadap Efisiensi Sterilizer Dan Kualitas Minyak Yang Dihasilkan,” Menara Ilmu, vol. XII, no. 10, pp. 1-8, 2018. 
